1 Universidade Federal de São Paulo (Unifesp), campus Baixada Santista, Departamento de Políticas Públicas e Saúde Coletiva Santos (SP), Brasil. rosilda.mendes3@gmail.com

2 Universidade Estadual de Campinas (Unicamp), Faculdade de Ciências

Médicas, Departamento de Saúde Coletiva - Campinas (SP), Brasil.

aneirosfernandez@gmail.com

3 Universidade Estadual de Campinas (Unicamp), Faculdade de Ciências Médicas, Departamento de Saúde Coletiva - Campinas (SP), Brasil.

danielesacardo@gmail.com

\section{Promoção da saúde e participação: abordagens e indagações}

\section{Health promotion and participation: approaches and inquiries}

\author{
Rosilda Mendes ${ }^{\mathbf{1}}$, Juan Carlos Aneiros Fernandez ${ }^{2}$, Daniele Pompei Sacardo ${ }^{\mathbf{3}}$
}

RESUMO Este ensaio discute as diferentes abordagens da promoção da saúde e da participação e suas implicações no sentido de contribuir para a construção de novas práticas e compromissos em torno da produção social da saúde. Defende a ideia de que práticas de promoção da saúde podem ser ativadoras de potência de ação para construir medidas que resultem em fortalecimento dos sujeitos e das coletividades, na ampliação da autonomia e no fomento da participação e das redes. A intenção deste artigo é compartilhar ideias, além de ser um convite a afastarmo-nos das receitas e das reproduções, a fim de inventarmos nossos próprios modos de construir a promoção da saúde.

PALAVRAS-CHAVE Promoção da saúde; Participação social; Autonomia.

ABSTRACT This essay discusses the various approaches to health promotion and participation and its implications in the sense of contributing to the construction of new practices and undertakings around the social production of health. It defends the idea that health promotion practices can be power activators of actions to construct measures which result in the strengthening of subjects and collectivities, in the increase of autonomy and in the increasing of participation and networks. The intention of this article is to share ideas, as well as being an invitation to move away from revenues and reproductions, in order to invent our own methods of constructing health promotion.

KEYWORDS Health promotion; Social participation; Autonomy. 


\section{Promoção ou promoções da saúde?}

A provocativa indagação traz em si a ideia de que a promoção da saúde pode ser analisada a partir de diferentes abordagens. Nosso intuito é mostrar que esse permanece um campo em construção e convive com uma pluralidade de concepções (modos de pensá-la) e de agir (intervenção). É também nossa intenção apresentar significados que possam contribuir para a construção de novas práticas e compromissos públicos em torno da produção social da saúde.

Com a finalidade de reforçar um conceito mais amplo de promoção da saúde, nosso ponto de partida é questionar a ideia de que suas práticas se limitem a identificar os efeitos nocivos de determinados comportamentos e hábitos, e, assim, atuar sobre os indivíduos mais expostos ao risco, normatizando seus estilos de vida.

Vamos refletir um pouco mais sobre essa ideia. Não é incomum na prática em saúde o pensamento de que, quando um 'desvio' aparece, basta educar as pessoas, pois a inteligência, a ciência e a razão seriam suficientes para corrigir essas irregularidades. O raciocínio que está por trás é o de que, a partir de um diagnóstico da situação - o que as pessoas desconhecem ou conhecem erroneamente -, teríamos o tratamento: o conteúdo, as técnicas e os métodos educativos persuasivos necessários para corrigir a conduta. A não adesão à ideia se deveria à ignorância e à falta de informação (MELO, 1987). Se tomarmos como exemplo o tabagismo - cujo uso está associado à incidência de câncer e doenças cardiovasculares, evidência científica aceita por vários trabalhos científicos -, a despeito das inúmeras campanhas sanitárias de aconselhamento e controle, constataremos que persistem comportamentos inalterados de pessoas que, mesmo obtendo informações sobre suas implicações nocivas, ainda assim, continuam fumando.
Isso faz pensar que não basta conhecer o funcionamento das doenças e eleger mecanismos para o seu controle, supondo haver apenas falta de conhecimento das informações técnico-científicas adequadas. Percebe-se, também, que lidamos com temas complexos e singulares, como a saúde e a vida, relacionados amplamente com o contexto social, a cultura e com as subjetividades, cuja magnitude as evidências científicas parecem não alcançar.

Esse e outros tantos exemplos, como os de ações contra o sedentarismo ou em favor de uma alimentação mais saudável, poderiam, também, ser citados por seguirem esta mesma lógica: focalizar o fazer (intervir) na aquisição das informações científicas e na transformação dos comportamentos dos indivíduos. Reforçam-se, assim, discursos e práticas que objetivam delegar cada vez mais aos sujeitos e grupos sociais específicos a tarefa de cuidarem de si mesmos. Isso poderia ser positivo apenas se não estivesse acompanhado de uma desresponsabilização do Estado na oferta das condições para esse cuidado e se considerasse, de fato, as escolhas dos sujeitos.

A cultura normativa própria dessa abordagem é ainda bastante expressiva no setor da saúde, onde tudo é sempre regulado por normas centralizadas e onde se estabelece o que deve ser feito e como deve ser feito, reforçando atitudes hierarquizadas e autoritárias, de responsabilização das pessoas nas mudanças de condições sanitárias e na maneira de viver. Sofisticam-se estratégias de culpabilização dos indivíduos pelos males que os acometem e de persecutoriedade (STOTZ; ARAÚJO, 2004). Uma perigosa armadilha é a de, mesmo sem querer, transformarmos os 'sujeitos' em 'objetos' de intervenção, retirando sua capacidade de refletir, de escolher, de decidir, de transformar, de analisar e (por que não?) de discordar de nossas 'boas intenções' enquanto profissionais da saúde.

Discutir criticamente esses enfoques 
centrados na informação para a mudança de comportamento traz a necessidade de refletir sobre os processos comunicacionais e educativos que permeiam e são mediadores das práticas em saúde. 'Ninguém escapa da educação', lembra bem Brandão (1981). Mas de que educação estamos falando? Queremos reforçar posições circunscritas ao universo da prescrição e das normas ou desejamos apoiar posições inclusivas, dialógicas, que propiciem a participação e a implicação na tomada de decisões?

Muitas dessas visões a respeito da promoção da saúde vêm sendo historicamente construídas e se valem de conceitos clássicos que orientam a produção do conhecimento na área de saúde, especialmente da medicina. Historicamente, a promoção da saúde foi referida pelo sanitarista Henry Sigerist, em 1946, como uma das quatro funções da medicina, ao lado da prevenção de doenças, do tratamento e da reabilitação de doentes. Nos anos de 1960, ganha destaque o preventivismo, do modelo da História Natural da Doença, de Leavell e Clark, que trouxe a discussão da doença como um processo e sua múltipla causalidade.

Os objetivos finais de toda atividade médica, odontológica e de saúde são a promoção da saúde, a prevenção de doenças e o prolongamento da vida. (LEAVELL; CLARK, 1976, P. 11).

Os autores localizaram a promoção da saúde no primeiro nível das medidas preventivas, portanto, antes da instalação da doença no indivíduo.

Não é sem motivo, portanto, a recorrente discussão sobre as aproximações e distinções entre a prevenção de doenças e a promoção da saúde, pois, nessa perspectiva, mantem-se o foco sobre as doenças e não sobre os aspectos salutogênicos, de proteção à saúde (ANTONOVSKY, 1996), que caracterizam a promoção da saúde. Fundamentadas no modelo de Leavell e Clark (1976), as práticas de promoção da saúde resumir-se-iam a recomendações voltadas às mudanças de hábitos. Resultariam em aconselhamentos e educação sanitária adequada ao comportamento 'mais saudável' de indivíduos e grupos, dando às práticas um sentido instrumental e normativo.

Esse modelo ganhou hegemonia ao longo do século XX e fundou-se na objetividade, na neutralidade e na universalidade do saber científico, bem como nos modelos clássicos de explicação do processo saúde-doença, pressupostos que sustentam a prescrição como única escolha possível para o alcance do bem-estar das pessoas, independentemente das suas inserções sócio-histórica e cultural. Campo fértil para proliferação de discursos e práticas preventivistas, o próprio sistema capitalista conduz à concepção de que a doença seja vista como

[...] a própria razão de ser do sistema produtivo, isto é, como um desequilíbrio constitutivo, levando, por isso, à permanente e obrigatória produção do retorno ao status quo ante, na medida em que esse retorno significa a preservação da vida. (LEFÉVRE; LEFÉVRE, 2007, P. 17).

Por outro lado, reconhece-se a diversidade de formatos, experiências, projetos, programas, ações e iniciativas de promoção da saúde sendo levados a cabo que, invariavelmente, busca potencializar processos de mudança ao vincular a promoção da saúde à construção da autonomia dos sujeitos, à participação, a incessantes movimentos instituintes, a processos de subjetivação e atribuição de significados e sentidos para as experiências vividas.

Podemos, também, pensar a promoção da saúde do ponto de vista da relação entre o saber e o fazer, ou na perspectiva da inter-relação entre teoria e prática. Esse par teoria/prática nos remete, sobretudo, a uma perspectiva política e crítica, dando lugar privilegiado aos sentidos da palavra 'reflexão' e a expressões como 'reflexão crítica', 'reflexão emancipadora', 'reflexão sobre 
prática e não prática' (BONDÍA, 2002).

Isso tudo pode ser suficientemente conhecido, posto que, embora possa persistir em nosso meio certa separação entre a teoria e a prática - o que é próprio da racionalidade moderna -, reconhece-se que nos últimos anos tem havido empenho do campo da promoção da saúde em buscar articular e aproximar essas duas vertentes, concebendo-as de maneira integrada enquanto uma 'práxis ético-política'. Práxis essa que busca articular, também, as práticas cotidianas aos sentidos que atribuímos a elas, que, por sua vez, são histórica e socialmente construídos e legitimados, resultantes de interesses e concepções em disputa (IGLESIAS; DALBELLO-ARAÚJO, 2011).

A abordagem da promoção da saúde que dialoga com essa concepção não pretende 'resolver' as tensões e ambiguidades que possam existir no âmbito da temática, mas dar lugar e reconhecê-las como parte da 'construção de sentidos' para cada um desses conceitos colocados lado a lado e tantos outros que dizem respeito à promoção da saúde: produção social da saúde, determinação do processo saúde-doença, intersetorialidade, participação, autonomia, riscos, vulnerabilidades, territórios, construção de redes, atenção à saúde, corresponsabilidades etc.

Bondía (2002) nos lembra que as palavras produzem sentidos, criam realidades e, às vezes, funcionam como 'potentes mecanismos de subjetivação', pois é com elas que damos sentido ao que somos e ao que nos acontece, de como correlacionamos as palavras e as coisas, de como nomeamos o que vivemos ou o que sentimos. Nomear o que fazemos ou intitulamos 'promoção da saúde' como um 'referencial', uma 'prática', uma 'práxis ético-política' ou como 'experiência dotada de sentido' não é somente uma questão terminológica. Tratase de uma opção ou escolha entre paradigmas, reconhecendo os riscos implicados nessa ação.

Czeresnia (2003, P. 49) nos alertou que "promover saúde envolve escolha e isso não é da esfera do conhecimento verdadeiro, mas do valor". Partindo dessa consideração e seguindo com ela, abre-se espaço para que a promoção da saúde se inscreva definitivamente no campo da ética, e, consequentemente, a emoção, o afeto, a subjetividade e os sentimentos passionais não apenas componham, mas tornem-se imperativos nos seus pressupostos, desenvolvimento e 'práxis'.

Segundo a mesma autora, tratar-se-ia de buscar por meio da promoção da saúde

a renovação de velhas filosofias que foram esquecidas e marginalizadas pela crença desmedida na razão e no poder de controle e domínio do homem. (CZERESNIA, 2003, P. 44).

Com esse argumento, apoiamo-nos em Espinosa, filósofo da alegria e da liberdade, conforme expressão usada por Chauí (1995), o qual defende o deslocamento do âmbito 'político' para o campo da 'ética' e desta para o das 'emoções'.

É impulsionado pelos afetos e pela paixão que o julgamento pode decidir que um determinado comportamento corresponde ao bem e que determinada ação deva ser evitada. (ESPINOSA APUD SAWAIA, 2001, P. 124).

Para ele, a capacidade do homem de ser afetado e o modo como o é, é determinante à constituição dos valores éticos, pois o que faz algo ser bom ou mau é o afeto do qual deriva. Sua ideia de 'bom' corresponde ao desejo de ser feliz e à valorização de tudo que sirva à expansão da vida, o que, no nosso caso, equivaleria à produção da saúde, à ampliação da qualidade de vida, à defesa da vida.

As proposições espinosianas fundamentam-se no conceito de potência de ação, "entendido como o direito que cada indivíduo tem de ser, de se afirmar e de se expandir" (SAWAIA, 1999, P. 111), cujo desenvolvimento é condição para se atingir a liberdade.

A promoção da saúde como potência trata da passagem da passividade à atividade, da heteronomia à autonomia, da técnica à ética, da razão à emoção, do instituído ao instituinte. 
Isso não significa colocar cada uma dessas palavras-conceitos em posições antagônicas e, com isso, ter de decidir por um 'ou' outro polo. Ao contrário, significa o reconhecimento de inter-relações dinâmicas que são, ao mesmo tempo, objetivas e subjetivas, que há tendências ora para tencioná-las, ora para colocá-las lado a lado.

Algumas recentes proposições de promoção da saúde guardam estreitas afinidades com essa perspectiva mais ampliada (IGLESIAS; DALBello-AraUjo, 2011; SILVA ET AL., 2013). Ao afirmar que promoção de saúde "acontece a partir da oportunidade que os sujeitos têm de ouvir a si mesmos e aos outros, e de reformular, recriar seus modos de pensar e de estar no mundo, confrontando concepções por vezes enrijecidas e adoecedoras", Silva et al. (2013, P. 1005) apontam a relevância de se produzir espaços de 'bons encontros' que potencializem sujeitos e promovam saúde.

Adotar como objetivo fundamental da promoção da saúde a ativação da potência de ação significa construir ações, iniciativas, programas ou projetos que de fato resultem em fortalecimento dos sujeitos e das coletividades para 'lutar contra a servidão', ou seja, para passar da passividade para a atividade, pelo desejo de ser livre e de ser feliz. Significa, também, ampliar a autonomia e o poder dos atores locais e das instâncias locais de gestão; conhecer profundamente as dinâmicas territoriais; estabelecer pactos e parcerias locais; fomentar a participação e as redes de ação intersetorial, incluindo novos atores na gestão; desenvolver métodos e técnicas de trabalho, experimentá-los, revisá-los e modificá-los. Significa, ainda, criar e recriar sentidos e significados acerca de nossas práticas e, sobretudo, dar espaços para as incertezas, para a experiência, para novos começos.

\section{Sobre a perspectiva participativa da promoção da saúde}

Poderíamos parafrasear Canguilhem (1995) afirmando que a participação é um conhecimento vulgar, com o mesmo sentido que esse autor confere ao conhecimento da saúde, isto é, que todo mundo ou qualquer um de nós sabe o que ela é. Em razão disso, habituamo-nos a refletir sobre a participação, sua importância, alcance e limites, sem considerar, necessariamente, sua historicidade. Com frequência, convocamos e somos convocados a participar de algo, e isso tem a ver com o tempo em que estamos vivendo.

Desde a transição democrática, ocorrida nos anos 1980, há uma forte constância do tema participação no discurso político nacional. As políticas públicas e as agendas sociais que se desenvolveram a partir desse período, por exemplo, reafirmam a ideia da participação como pressuposto, como método e como resultado a ser alcançado (WESTPHAL ET AL., 2013).

Em meados da década de 1970, o cenário que envolve o tema sofreu uma inflexão mobilizada por três ordens de fatores isolados ou combinados de diferentes formas: uma tangível desilusão das populações com relação às instituições políticas construídas nesse longo período histórico; o surgimento de 'novos grupos de interesses' e movimentos de caráter identitário; e as reformas nos Estados e em suas estruturas burocráticas (CORTES, 1996).

O contexto que influencia a participação nesse período leva, por um lado, ao desenvolvimento da perspectiva da participação social, descentrada - de um lócus privilegiado da relação indivíduo-instituições políticas - e policentrada - em diversos espaços públicos abertos pelas práticas sociais cotidianas. Por outro lado, influencia contemporaneamente três tipos de abordagens bastante frequentes da participação social, sobretudo no âmbito da saúde (VIANNA; CAVALCANTI; CABRAL, 2009), quais sejam: o estímulo à ampliação da cidadania e ao empoderamento dos participantes; a qualificação da gestão/boa governança; a ampliação do autocuidado/controle da própria vida (e saúde). 
Essas abordagens, em diálogos com as situações empíricas ou com as experiências desenvolvidas, acabam por conformar a problemática da participação em torno do sentido que ela pode ter com relação à conservação e/ou transformação das condições sociais dadas, isto é, nossos repertórios herdados e nossas instituições.

Assim, no tocante ao primeiro grupo de abordagens referentes à cidadania e ao empoderamento, a problemática se daria em torno do caráter 'regulador' ou, contrariamente, 'emancipador' da dimensão pedagógica da participação (SANTOS, 1993). No segundo grupo, referente à gestão/governança, a dimensão de controle social da participação teria de distinguir entre a tomada de decisões ou a legitimação de decisões tomadas por outros (MILANI, 2008). Por fim, no terceiro grupo de abordagens relativas ao autocuidado/controle, uma dimensão produtora de expertise da participação teria que separar a construção de ações autônomas da combinação deletéria entre (des) responsabilização do Estado e corresponsabilização dos cidadãos, como destacamos anteriormente.

Ao discutir a prática das políticas sobre os determinantes sociais da saúde, a Organização Mundial da Saúde (OMS) afirma que

a participação das comunidades e da sociedade civil no desenvolvimento de políticas públicas, no monitoramento de sua implementação e na avaliação de seus resultados é essencial para qualquer conjunto de ações sobre os determinantes sociais. (OMS, 2011, P.

18).

Após considerar o valor intrínseco e o valor instrumental da participação e chamar a atenção para a necessidade de se enfrentar os históricos de exclusão social mediante o fomento a ela, esse mesmo texto apresenta a figura 1, a seguir - adaptada de outras fontes -, que nos parece esclarecedora da problemática que gira em torno da

Figura 1. Técnicas para se obter a participação das comunidades no processo de formulação de políticas

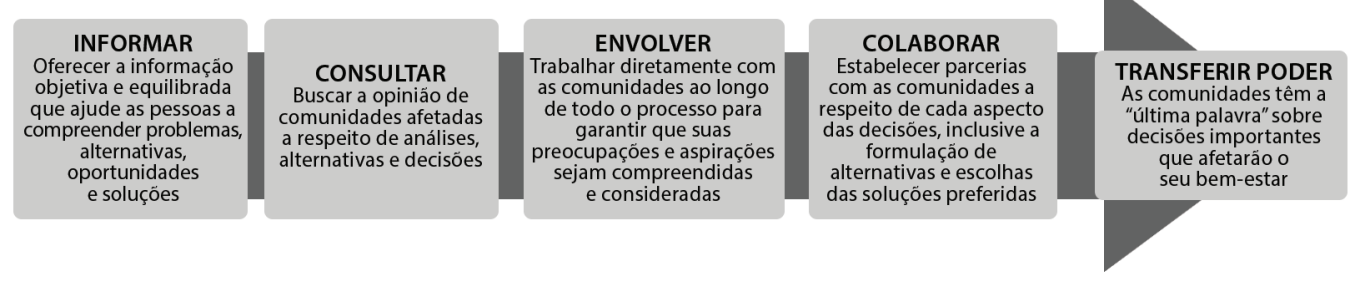

Fonte: OMS (2011).

participação propriamente dita e, também, da discussão sobre essa temática.

Podemos, com certa facilidade, perceber tudo o que está implicado no trajeto representado por essa figura, que vai do 'informar' ao 'transferir poder' (BRASIL, 2013), entretanto, parece menos fácil perceber o que, de fato, precisamos conhecer ou validar como conhecimento para fazer valer esse trajeto, para fazer com que aquilo que parece tão óbvio e promissor possa estar mais presente entre nós.

Por essa razão, realizamos, a seguir, uma discussão conceitual sobre a participação, 
que pretende fornecer uma base sólida para desenvolvê-la nessa perspectiva promissora para a promoção da saúde.

\section{Uma definição de participação e suas implicações}

A Organização Pan-Americana de Saúde (OPS; OMS, 1999) afirma que a participação é um processo social inerente à saúde e ao desenvolvimento.

Selecionamos essa definição pelo que ela informa acerca de uma concepção abrangente da participação que nos interessa discutir. Devemos considerar diferentes elementos vinculados a esse entendimento para mais bem compreender o que ele, de fato, significa. Isso quer dizer que precisamos considerar tanto a ideia de 'processo' vinculada à participação quanto nossas noções de saúde e de desenvolvimento, além de quanto essas noções são inseparáveis da participação.

Quanto à ideia de processo, caberia destacar que essa é uma das marcas ou características fundamentais da promoção da saúde e das ações desenvolvidas em seu âmbito. Quer se trate de pensar sobre a transformação das condições de vida e saúde dos indivíduos e populações, quer se trate de construir novas formas de intervenção, mecanismos ou programas de atenção e cuidado, a promoção da saúde valoriza sempre os processos em que isso se dá e operacionaliza, isto é, ela tem sua atenção voltada também para aquilo que se produz à medida que se está pretendendo produzir alguma coisa.

A experiência vivida e significada pelos atores/sujeitos em cada iniciativa, as novas ou modificadas relações que se estabelecem a partir dessa vivência, as aprendizagens e descobertas que decorrem dela são, nesse sentido, tão importantes quanto é chegar aos resultados previstos ou esperados por essa mesma experiência.
Considerar os 'processos' é, portanto, perceber que as iniciativas transcorrem em um determinado tempo, sob dadas condições e em meio a diferentes interesses, desejos e lógicas de ação, razão pela qual as intercorrências, surpresas, inovações, 'idas e vindas', sucessos e insucessos sejam a expressão da participação de diferentes sujeitos da ação social e política que essas iniciativas ensejam.

Dessa forma, considerar o processo de uma dada iniciativa é uma oportunidade de ultrapassar a mera lógica do 'estímulo/resposta' que ela pode representar, ou seja, promover uma ação ' $x$ ' para obter um resultado 'y', para alcançar uma lógica de produção social, isto é, um alargamento do espaço público no qual a sociedade produz a si mesma. Apenas assim podemos esperar que as iniciativas contribuam para a transformação não apenas do 'outro' - o paciente, o usuário, o cliente -, mas de uma dada realidade social, na qual ele e também nós vivemos.

As ações ou iniciativas da promoção da saúde, nessa perspectiva, deixam de corresponder apenas a inovações de ordem técnica na oferta e na prestação de serviços para se converterem na instauração de espaços para a produção social de saúde, informadas como são pela ideia de que os indivíduos e grupos, de fato, participam desses processos, atribuindo sentidos, animando ou esvaziando a importância dos conteúdos e ações propostas, fazendo seus juízos e enviando mensagens direta ou indiretamente a respeito do que sejam suas necessidades e desejos.

Com esse entendimento a respeito da participação como um processo, um 'fazer fazendo' que decorre da experiência vivida por sujeitos, podemos mais bem compreender sua inerência relativa à saúde e ao desenvolvimento a que se refere a definição da OMS que destacamos acima.

Detenhamo-nos, primeiramente, ao exame dessa inerência com relação à saúde pelo que ela tem de oportuno, para reforçarmos a concepção de saúde com a qual se 
alinha a área da promoção da saúde e da qual pode extrair potentes insumos para promover transformações desejadas nas condições de vida e saúde das populações.

Referimo-nos à ideia da positividade da saúde que se contrapõe ao seu entendimento como a mera ausência de doenças. Quer seja partindo da definição de saúde como um estado de bem-estar físico, social e espiritual - tal como desenvolvido pela OMS -, quer seja como capacidade para enfrentar as adversidades do viver - tal como desenvolvido por Canguilhem (1995) -, o entendimento a respeito do que seja a saúde requer a participação dos sujeitos (indivíduos e grupos).

O conceito de saúde reflete a conjuntura social, econômica, política e cultural. Ou seja: saúde não representa a mesma coisa para todas as pessoas. Dependerá da época, do lugar, da classe social. Dependerá de valores individuais, dependerá de concepções científicas, religiosas, filosóficas. O mesmo, aliás, pode ser dito das doenças. Aquilo que é considerado doença varia muito. Houve época em que masturbação era considerada uma conduta patológica capaz de resultar em desnutrição [...]. Houve época, também, em que o desejo de fuga dos escravos era considerado enfermidade mental: a drapetomania (do grego drapetes, escravo). (SCLIAR, 2007, P. 30).

Não obstante o espetacular desenvolvimento técnico-científico dos conhecimentos em saúde que o Ocidente, de modo geral, promoveu nos últimos cinco séculos, sobretudo com relação ao conhecimento de doenças e formas de enfrentá-las, a saúde como tal segue sendo percebida a partir da experiência subjetiva e cultural dos indivíduos. É tanto no âmbito de nossa cultura e sociedade que entendemos o que é ser saudável quanto na experiência idiossincrática de cada um na definição de um sentido para o bem-estar e para o sofrimento (CAPONI, 2003).

Considerar a saúde em uma dimensão positiva corresponde a incluir elementos que vão além do aspecto biológico dos órgãos, tecidos e funções do 'corpo vivo', alcançando aspectos relacionados ao 'corpo vivido' (ORTEGA, 2008), isto é, à experiência dos indivíduos. Nessa experiência estão presentes fatores estressores e protetores decorrentes das diversas formas que indivíduos e grupos encontraram para estabelecer relações com eles mesmos, com os outros e com o seu meio.

Por essa razão, todo o conhecimento técnico-científico em saúde pode não ser o bastante, mas apenas um dos elementos para a construção de um projeto de intervenção ou terapêutico adequado a cada caso ou situação. Junto a esse elemento deve ser colocada a experiência dos sujeitos, isto é, deve ser considerada sua participação, se o que se pretende é, de fato, a produção de projetos de sucesso prático e felicidade (AYRES, 2001), ou seja, a construção de projetos de vida saudáveis.

Se essa argumentação já parece suficiente para compreendermos por que a participação é um processo inerente à saúde, podemos prosseguir com a definição que tomamos como referência para nossa reflexão e examinar, então, as razões pelas quais a participação seria, também, inerente ao desenvolvimento.

Entendemos que seja o caso de explorar a ideia do desenvolvimento humano, ainda que as relações entre participação e desenvolvimento econômico tenham sido objeto de interesse de várias abordagens em torno da questão. O que nos interessa de modo particular é a dimensão da participação que remete diretamente às escolhas. É em torno disso que entendemos ser possível compreender a participação em perspectiva tão ampla quanto seja necessário.

A escolha a que nos referimos é a tomada de decisões. Decisões corriqueiras e/ou inesperadas, simples e/ou complexas, tomadas por gestos 'mecânicos' e/ou mediante reflexão, em ações que realizamos sós e/ou acompanhados, lembrando um passado e/ 
ou imaginando um futuro, baseando-nos nas tradições e/ou nos desejos de mudanças, repetindo e/ou criando situações.

Talvez fosse possível inventariar as naturezas, os tipos, as formas e os contextos das decisões/escolhas, ainda que isso não pareça ser uma tarefa recomendável. Já as escolhas propriamente ditas jamais poderão ser encerradas em um inventário.

Como seres da cultura, aprendemos desde o processo de socialização primária (BERGER; LUCKMAN, 1991), quando somos ainda muito pequenos, a responder às situações criadas, a fazer escolhas e a tomar decisões. E quando aprendemos a fazer isso, jamais paramos de fazê-lo. Partimos sempre de um dado repertório colocado a nossa disposição por nossa cultura e, ao utilizá-lo, vamos transformando-o de modo a torná-lo mais adequado a nossas necessidades e aspirações.

Não é uma escolha em particular, qualquer que seja ela, o que mais importa, mas, sim, o próprio ato de escolher. Se pensarmos nas outras culturas, nos outros de nossa cultura e, por fim, nos outros possíveis de nós mesmos, perceberemos com maior clareza o quanto esse gesto tem sido responsável pelo desenvolvimento da diversidade de nossa espécie, pelo desenvolvimento humano como tal.

A participação como processo social inerente ao desenvolvimento encontra, assim, sua fundamentação. É a participação dos indivíduos e grupos usando, julgando e transformando seus repertórios culturais herdados o que os trouxe até os pontos nos quais se encontram. E é mantendo esse processo que eles conferem um sentido a seu presente e vão construindo o seu futuro.

Exploremos, então, o que decorre de considerar a participação nos termos acima expostos, que procuraram compreendê-la como 'um processo social inerente à saúde e ao desenvolvimento'. Para tanto, poderíamos colocar a seguinte questão: que diferença pode fazer uma argumentação como essa que vimos desenvolvendo?
Conforme entendemos, com essa abordagem não caberia qualquer hesitação com relação a desencadear as ações de promoção da saúde voltadas aos mais variados públicos em uma perspectiva participativa. Se os indivíduos e grupos elaboram sucessiva e permanentemente os significados de suas experiências, deflagrar processos de natureza participativa corresponde menos a uma inauguração que dependa do idealizador ou responsável pela experiência e mais a uma oportunidade de potencializar os efeitos que essa experiência pode ensejar.

De acordo com o dicionário Aurélio, 'encontro' significa a posição face a face com uma pessoa ou coisa ou a colisão de dois corpos. $\mathrm{O}$ encontro, como um embate entre duas forças, é o momento vital para a formação e a criação de qualquer coisa ou evento (ANDRADE; SACARDO; FERNANDEZ, 2010).

O reconhecimento de que todos participam da atribuição de significados faz com que nos voltemos mais para o lugar dos 'encontros' do que para o das 'prescrições' (já muito questionado por nós). A diferença, nesse caso, é que em tal abordagem o 'outro' deixa de ser o objeto da ação e/ou transformação que julgamos necessária e passa a ser um sujeito reconhecido e legitimado da ação e/ou transformação. Da mesma forma que não se trata de considerar apenas como o outro pode 'lidar' com um tema, assunto, medida, iniciativa ou o que quer que seja, mas, sim, de considerar o que nosso encontro com relação a isso pode produzir, e, de fato, produz. É nisso, no encontro, que reside a potencialização da experiência.

Com essa abordagem, nós já não podemos reduzir a análise sobre processos participativos à responsabilização do outro por aquilo que ele não sabe, não percebe e sobre o que não tem consciência. $\mathrm{O}$ que é preciso considerar a partir dela é o quanto, de fato, compreendemos sobre as escolhas, decisões e participação do outro; se ouvimos ou estamos interessados em ouvir o que ele diz; se consideramos poder aprender quando nos 
encontramos com ele; se criamos as condições para sua participação tão livre quanto possível; se queremos participar de um processo de desenvolvimento ou se queremos que ele desenvolva nosso projeto.

Ao considerarmos questões desse tipo, podemos perceber como uma concepção tão ampla de participação se aplica a nossas situações cotidianas e profissionais. Por mais que pareça distante a concepção da participação como inerente à condição humana daquela participação que identificamos, ou que não conseguimos identificar, corriqueiramente, nossas chances de promover transformações se ampliam à medida que incluímos, de fato, o outro como um sujeito de potência nesses processos.

Infelizmente, o inverso disso, ou seja, a despotencialização do outro, vem informando, ao longo da história, parte considerável das ações nos âmbitos social, cultural e político - e também no da saúde -, cujo resultado tem sido a manutenção das estratégias de dominação e exclusão.

Se nos ativermos a isso, podemos mais bem compreender o sentido de se definirem ações à revelia dos interesses daqueles a quem essas ações se destinam, ou seja, sem a participação dos envolvidos por ela. O sentido de mobilizar indivíduos e grupos sem conferir a eles o poder de decidir sobre as questões em pauta ou desconsiderar suas decisões quando foram solicitadas. E, também, a delimitação rígida do lugar onde participar, do tempo em que se deve fazê-lo, do objeto sobre o qual se deve ater o participante ou da forma adequada de participar.

Podemos facilmente identificar e relembrar situações nas quais lógicas como essas tenham sido empregadas, e, ao fazermos isso, não podemos renunciar à reflexão sobre o impacto que elas produzem ou podem ter produzido sobre a manutenção do status quo e, consequentemente, ao apego e ao envolvimento de indivíduos e grupos em processos desse tipo.

Pensemos sobre a 'força' dessa lógica utilizando como metáfora uma moeda. Em uma das faces da moeda, poderíamos ler: 'fica tudo como está'. Em outra face da moeda, leríamos: 'isso tudo não me interessa'. O valor da moeda, por fim, corresponderia a que 'a falta de interesse mantém as coisas como estão'. É uma lógica de despotencialização o que podemos perceber a partir dessa metáfora. É um foco que recai sobre o que falta no outro, o interesse, e, consequentemente, sobre a sua culpabilização.

Inversamente, numa lógica de potência, que a abordagem aqui desenvolvida parece ensejar, o valor da mesma moeda poderia ser: 'para ficar como está, isso tudo não me interessa'. Nesse caso, a falta de interesse não é tida como uma qualidade do outro, mas como a 'resposta' que ele dá a uma dada situação de manutenção do status quo. $\mathrm{O}$ foco, então, deveria recair sobre a transformação dessa situação, pois é ela que deve ser julgada e não o sujeito que a julgou.

Comparando o emprego das duas lógicas, podemos perceber que a diferença no resultado não é pequena e, também, que é toda ela devida ao lugar que reservamos aos outros e, conseguintemente, a nós mesmos, e vice-versa. Podemos explorar isso relativamente em diferentes situações. É o caso de considerarmos o quanto nossas convicções acerca de nossos gestos, ações, projetos, programas e conhecimentos parecem poder prescindir do julgamento feito por outrem. Da mesma forma que é o caso de considerar o quanto podemos agir e realizar baseados em lugares legitimados de poder que ocupamos sem nos preocuparmos com os contextos dessa legitimação, isto é, ingenuamente, dirigir-se ao diálogo esquecendo-se de que já se é parte dele (AYRES, 2001).

Evidentemente, não se trata de modificar a 'curvatura da vara' para o lado oposto, transformando toda a problemática da participação, antes referida ao outro, em problemática referida a nós mesmos. O que esta abordagem persegue é a promoção de encontros, a implicação dos diferentes sujeitos, a 
ocupação do espaço público - aquele espaço entre dois (ARENDT, 2007), que é o lugar para a 'concertação'. O que esta abordagem descarta é o recurso a qualquer álibi para não se empreenderem os processos participativos em todas as situações. Nesta abordagem, esses processos participativos são considerados essenciais para o empoderamento de indivíduos e grupos.

Ao trazermos para a reflexão questões que dizem respeito a nós - que somos aqueles para os quais a participação tem grande importância, devendo, portanto, ser estimulada e facilitada-, o que pretendemos é destacar a existência de um contexto que atinge a todos e que, não sendo considerado, transforma-se em armadilhas. Trata-se do contexto das relações entre o instituído e o instituinte, isto é, de uma dinâmica das instituições (CASTORIADIS, 1987; LOURAU, 1975; MAFFESOLI, 1997).

Nosso lugar como agentes públicos da saúde, nossas especialidades profissionais, os conhecimentos e as evidências científicas sobre as quais nos baseamos, nossos projetos e aquilo com o que nos comprometemos seriam apenas alguns exemplos daquilo que nos acompanha em nossas ações e iniciativas.

Pensar na participação, portanto, requer o exame sobre que enfrentamento institucional se está realizando, isto é, examinar se estamos reproduzindo, ressignificando ou criando instituições e se o fazemos baseados na autonomia ou submetidos à heteronomia. $\mathrm{E}$ as armadilhas a que nos referimos há pouco consistem em ignorar que as instituições são construções humanas, que somos responsáveis por sua manutenção ou transformação e, principalmente, que uma "sociedade só pode ser autônoma, isto é, livre para optar e se governar, se seus membros têm o direito e os meios de escolher e jamais renunciam a esse direito nem o entregam a outros" (BAUMAN, 2000, P. 141).

Bauman (2000) destaca que havia, na antiga Grécia, um preâmbulo a todas as leis criadas que dizia: 'é considerado bom pelo conselho e pelo povo.... O sentido disso é que a instituição, no caso, a lei, foi julgada como pertinente, mas, também, que ela cabe apenas enquanto for julgada como pertinente, ou seja, a instituição não estaria dada para sempre, mas deveria ser permanentemente examinada, sendo que a isso corresponde uma ação autônoma.

A tarefa de examinar permanentemente as instituições cabe a todos, e não fazê-lo tende a manter as coisas como elas estão, pois as instituições tendem a se autoconservar e se defender dos ataques a seus postulados para assegurar certa ordem e grau de previsibilidade para a ação humana, que, por certo, traduziram ou traduzem uma aspiração instituinte que as criou (CASTORIADIS, 1987). Sem esse exame, todos os atores ficam sem saber se estão fazendo escolhas e podem, inadvertidamente, apenas reproduzir aquilo que gostariam, na verdade, de transformar.

Assim, quando nos interessamos pela participação, o que deveria chamar nossa atenção são as relações de poder consolidadas, as estruturas e os aparelhos técnico-burocráticos que inibem as iniciativas de ação, os modelos disciplinadores e de controle que impedem a expressão livre da sociedade, as estratégias de preconceito e criação de estigmas com relação a determinados grupos, o peso das tradicionais divisões do papel que cabe a cada um desempenhar e do que informam como competências e incompetências.

\section{Considerações finais}

Historicamente, como profissionais da saúde, procuramos obter e oferecer respostas, mas o desafio que se coloca na contemporaneidade vai na direção de descobrir perguntas. No caso da promoção da saúde, ocorre o mesmo, e encontrar novas perguntas não nos parece uma questão simples, tampouco fácil ou confortável. Requer, no mínimo, interesse em se aproximar da realidade para conhecê-la e, talvez, compreendê-la para transformá-la.

A intenção deste artigo talvez se aproxime 
mais de algo que buscamos compartilhar - ideias, dúvidas e incertezas -, o que pode significar inovação e ser potente para nos transformar e aos sujeitos com quem interagimos. Não se trata, portanto, de mais uma tentativa de 'reinventar a roda', tampouco de 'fazê-la girar mais rápido'. Quiçá o convite seja para que o leitor embarque num veículo em movimento e, como um estrangeiro com um 'olhar' curioso, assustado ou encantado, possa se surpreender com o que vê, com o que escuta, com o que percebe, com o que o toca e ativa sua potência de ação para construir seus próprios projetos de promoção da saúde.

Entretanto, cabe a indagação: por que 'um olhar estrangeiro' se a promoção da saúde parece algo tão familiar e parte do cotidiano das ações do setor sanitário? Em geral, o estrangeiro enxerga o que o olho dos 'nativos' já havia se habituado a enxergar: o mesmo, o igual, o trivial, o que é conhecido. Um 'olhar de estranhamento', somado a 'atitudes de estranhamento' do que parece familiar, no nosso caso, ações, iniciativas, programas e projetos de promoção da saúde, pode possibilitar a transformação do familiar em estranho e do estranho em familiar; uma possibilidade de reconhecer na experiência do 'outro' formas diferenciadas de soluções para problemas comuns e, ao mesmo tempo, de descobrir, quando se olha para a própria experiência, um certo grau de 'miopia', por estarmos acostumados a naturalizar nossa experiência a partir dos nossos pré-conceitos. O estrangeiro está no olho de quem vê e não naquilo que é visto. Por isso, 'ser' estrangeiro implica abertura a uma mudança de olhar, de perspectiva, novas tentativas, dúvidas, acertos e erros.

Finalmente, fica o convite para afastarmo-nos das receitas, dos modelos, das reproduções para aguçarmos nosso 'olhar' motivados a inventar nossos próprios modos de construir a promoção da saúde como uma obra inacabada e em permanente elaboração, buscando refletir sobre os desafios, os paradoxos, as ambiguidades encontradas e, especialmente, os sentidos e significados das experiências vividas.

\section{Referências}

ANDRADE, E. A.; SACARDO, D. P.; FERNANDEZ, J. C. A. O "encontro" como espaço de experimentação e elaboração. In: FERNANDEZ, J. C. A. et al. (Org.). Juventude e Segurança: PROTEJO Osasco. São Paulo: Hucitec: Cepedoc Cidades Saudáveis, 2010, p. 85-100.

ANTONOVSKY, A. The salutogenic model as a theory to guide health promotion. Health Promot. Int., Oxford, v. 11, n. 1, p. 11-18, 1996.

ARENDT, H. A condição humana. 10. ed. Rio de Janeiro: Forense Universitária, 2007.

AYRES, J. R. C. M. Sujeito, intersubjetividade e práticas de saúde. Ciênc. saúde coletiva, Rio de Janeiro, v. 6, n. 1, p. 63-72, 2001.
BAUMAN, Z. Em busca da política. Rio de Janeiro: Zahar, 2000.

BERGER, P.; LUCKMANN, T. A construção social da realidade: tratado de sociologia do conhecimento. Petrópolis, RJ: Vozes, 1991.

BONDÍA, J. L. Notas sobre a experiência e o saber da experiência. Rev. Bras. Educ., Rio de Janeiro, n. 19, p. 20-28, abr. 2002.

BRANDÃO, C. R. O que é educação? São Paulo: Brasiliense, 1981.

BRASIL. Ministério da Saúde. Secretaria de Vigilância em Saúde, Departamento de Vigilância de Doenças 
e Agravos Não Transmissíveis e Promoção da Saúde. Curso de Extensão em promoção da saúde para gestores do SUS com enfoque no Programa Academia da Saúde. Brasília, DF: Ministério da Saúde: CEAD: UnB, 2013.

CANGUILHEM, G. O normal e o patológico. 4. ed. Rio de Janeiro: Forense Universitária, 1995.

CAPONI, S. A saúde como abertura ao risco. In: CZERESNIA, D. (Org.). Promoção da saúde: conceitos, reflexões, tendências. Rio de Janeiro: Fiocruz, 2003, p. 55-77.

CASTORIADIS, C. Encruzilhadas do labirinto II: domínios do homem. Rio de Janeiro: Paz e Terra, 1987.

CHAUÍ, M. Espinosa: uma filosofia da liberdade. São Paulo: Moderna, 1995

CORTES, S. M. V. As origens da participação na área da saúde. Saúde em Debate, Londrina, n. 51, p. 30-37, jun. 1996.

CZERESNIA, D. O conceito de saúde e a diferença entre prevenção e promoção. In: CZERESNIA, D.; FREITAS, C. M. (Org.). Promoção da saúde: conceitos, reflexões, tendências. Rio de Janeiro: Fiocruz, 2003, p. 39-53.

IGLESIAS, A.; DALBELLO-ARAÚJO, M. As concepções de promoção da saúde e suas implicações. Cad. Saúde Colet., Rio de Janeiro, v. 19, n. 3, p. 291-298, 2011.

LEAVELL, H. R.; CLARK, E. G. Medicina preventiva. São Paulo: McGraw-Hill; Rio de Janeiro: FENAME, 1976.

LEFÉVRE, F.; LEFÉVRE, A. M. C. Saúde como negação da negação: uma perspectiva dialética. Physis, Rio de Janeiro, v. 17, n. 1, p. 15-18, abr. 2007.

LOURAU, R. El analisis institucional. Buenos Aires: Amorrortu, 1975.

MAFFESOLI, M. A transfiguração do político: a tribalização do mundo. Porto Alegre: Sulina, 1997.

MELO, J. A. C. Educação sanitária: uma visão crítica.
Cadernos do CEDES, v. 4, p. 28-43, 1987.

MILANI, C. R. S. O princípio da participação social na gestão de políticas públicas locais: uma análise de experiências latino-americanas e européias. $R A P$, Rio de Janeiro, v. 42, n. 3, p. 551-579, maio/jun. 2008.

ORGANIZAÇÃO MUNDIAL DE SAÚDE (OMS).

Conferência mundial sobre os determinantes sociais da saúde. Diminuindo as diferenças: a prática das políticas sobre os determinantes sociais de saúde: documento para discussão. Rio de Janeiro, out. 2011. Disponível em: $<$ http://www.who.int/sdhconference/discussion_paper/ Discussion_Paper_PT.pdf>. Acesso em: 29 mar. 2015.

\section{ORGANIZAÇÃO PAN-AMERICANA DE SAÚDE} (OPS); ORGANIZAÇÃO MUNDIAL DE SAÚDE (OMS). Planificación local participativa: metodologías para la promoción de la salud en América Latina y el Caribe. Washington, DC, 1999 (PALTEX para Ejecutores de Programas de Salud, 41).

ORTEGA, F. O corpo incerto: corporeidade, tecnologias médicas e cultura contemporânea. Rio de Janeiro: Garamond, 2008.

SANTOS, B. S. O social e o político na transição pósmoderna. Lua Nova, São Paulo, n. 31, p. 181-203, dez. 1993.

SAWAIA, B. B. Participação social e subjetividade. In: SORRENTINO, M. (Coord.). Ambientalismo e participação na contemporaneidade. São Paulo: Educ: Fapesp, 2001, p. 115-134.

SAWAIA, B. B. O sofrimento ético-político como categoria de análise da dialética exclusão/inclusão. In: SAWAIA, B. B. (Org.). As artimanhas da exclusão: uma análise ético-psicossocial. São Paulo: Vozes, 1999, p. 97-118.

SCLIAR, M. História do conceito de saúde. Physis, Rio de Janeiro, v. 17, n. 1, p. 29-41, abr. 2007.

SILVA, G. G. S. et al. Momento dedicado à espera e à promoção da saúde. Psicologia: ciência e profissão, 
Uberlândia, v. 33, n. 4, p. 1000-1013, 2013.

STOTZ, E. N.; ARAÚJO, J. W. G. Promoção da saúde e cultura política: a reconstrução do consenso. Saúde soc., São Paulo, v. 13, n. 2, p. 5-19, ago. 2004.

VIANNA, M. L. T. W.; CAVALCANTI, M. L.; CABRAL, M. P. Participação em saúde: do que estamos falando?

Sociologias, Porto Alegre, v. 11, n. 21, p. 218-251, jan./jun. 2009.

WESTPHAL, M. F. Promoção da saúde e prevenção de doenças. In: CAMPOS, G. W. S. et al. Tratado de saúde coletiva. São Paulo: Hucitec; Rio de Janeiro: Fiocruz, 2006. p. 635-667.

WESTPHAL, M. F. et al. Práticas democráticas participativas na construção de agendas sociais de desenvolvimento em municípios do sudeste brasileiro. Ambiente \&t Sociedade, v. 16, p. 103-128, 2013.

Recebido para publicação em maio de 2015

Versão final em novembro de 2015

Conflito de interesses: inexistente

Suporte financeiro: não houve 